\title{
Trends in extended spectrum beta-lactamase (ESBL) producing Enterobacteriaceae and ESBL genes in a Dutch teaching hospital, measured in 5 yearly point prevalence surveys (2010-2014)
}

\author{
I Willemsen ${ }^{1 *}$, S Oome ${ }^{1}$, C Verhulst ${ }^{1}$, A Pettersson ${ }^{2}$, K Verduin $^{1}$, J Kluytmans ${ }^{1,3}$ \\ From 3rd International Conference on Prevention and Infection Control (ICPIC 2015) \\ Geneva, Switzerland. 16-19 June 2015
}

\section{Introduction}

For the execution of a good infection control policy we depend on information about the local endemic level of resistant microorganisms and resistance genes.

\section{Objectives}

This paper describes the trends in prevalence of ESBL producing Enterobacteriaceae (ESBL-E) and ESBL genes, measured in five consecutive yearly Point Prevalence Surveys (PPS), in a Dutch teaching hospital.

\section{Methods}

On the day of the survey all patient present in the hospital and day-care clinic (including patients on dialyses), were screened for rectal ESBL-E carriage. Rectal swabs (Eswab, Copan, Italy) were taken and cultured using an enrichment broth, containing cefotaxime $(0.25 \mathrm{mg} / \mathrm{L})$ and vancomycin $(8 \mathrm{mg} / \mathrm{L})(\mathrm{TSB}-\mathrm{VC})$ and a selective agar plate (EbSA, Alpha-Omega, Netherlands). Both phenotypical and genotypical methods were used to detect the production of ESBL and presence of ESBL-genes. Isolates containing an identical ESBL gene, from patients that were admitted on the same ward, were selected for Amplified Fragment Length Polymorphism typing to identify clonal relatedness.

\section{Results}

Out of 2,695 patients who were screened and evaluable, 135 (5.0\%) were positive for ESBL-E. E. coli was most frequently found (112/145), followed by K. pneumoniae (9/145), and

'Laboratory of Microbiology and Infection control, Amphia Hospital, Breda, Netherlands

Full list of author information is available at the end of the article
E.cloacae (7/145). The ESBL-E prevalence was stable over the years. In all PPSs CTX-M ESBLs were the most prevalent ESBL type. Over the years, a decrease in CTX-M-1-1 like ESBL genes was observed, starting with a proportion of $44 \%$ in $2010,34 \%$ in $2011,22 \%$ in $2012,24 \%$ in 2013 to $25 \%$ in $2014(p=0.026)$. Overall $5.2 \%$ of all ESBL-E were acquired by nosocomial transmission based on epidemiological linkage and molecular typing of the strains.

\section{Conclusion}

During this 5-year period the prevalence of rectal ESBL-E carriage was stable and only a minority was caused by nosocomial transmission. A relative decrease of CTX-M1-1 like ESBL genes was observed. As this is the most prevalent ESBL gene in poultry, this decrease might be related to the strong $(>60 \%)$ decrease in the use of antibiotics in poultry in our country in the same period.

\section{Disclosure of interest}

None declared.

\section{Authors' details}

'Laboratory of Microbiology and Infection control, Amphia Hospital, Breda, Netherlands. ${ }^{2}$ Department for Medical Microbiology and Infection control, VU University Medical Center, Amsterdam, Netherlands. ${ }^{3}$ Julius Center for Health Sciences and Primary Care, UMC Utrecht, Utrecht, Netherlands.

Published: 16 June 2015

\section{doi:10.1186/2047-2994-4-S1-P123}

Cite this article as: Willemsen et al:: Trends in extended spectrum beta-lactamase (ESBL) producing Enterobacteriaceae and ESBL genes in a Dutch teaching hospital, measured in 5 yearly point prevalence surveys (2010-2014). Antimicrobial Resistance and Infection Control 20154 (Suppl 1):P123. 